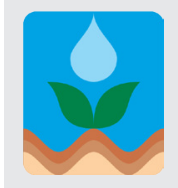

\author{
Revista Brasileira de Engenharia Agrícola e Ambiental \\ v.18, n.8, p.839-843, 2014 \\ Campina Grande, PB, UAEA/UFCG - http://www.agriambi.com.br \\ Protocolo 073.13 - 18/03/2013 • Aprovado em 07/03/2014
}

\title{
Quitosana e fitorreguladores na indução da organogênese direta em cultivar de algodão colorido
}

\author{
Taiza da C. Soares 1 , Flávia M. S. Sales², José W. dos Santos ${ }^{3} \&$ Julita M. F. C. Carvalho ${ }^{4}$ \\ ${ }^{1}$ Laboratório Cultivo de Tecidos, Embrapa Algodão. Campina Grande, PB. E-mail: taizabiologa@gmail.com (Autor correspondente) \\ ${ }^{2}$ Laboratório Cultivo de Tecidos, Embrapa Algodão. Campina Grande, PB. E-mail: flaviasales_bio@hotmail.com \\ ${ }^{3}$ Embrapa Algodão. Campina Grande, PB. E-mail: jose-wellingthon.santos@embrapa.br \\ ${ }^{4}$ Embrapa Algodão. Campina Grande, PB. E-mail: julita.carvalho@embrapa.br
}

\section{Palavras-chave:}

cv. BRS rubi

cultivo in vitro

superbrotamento

D-glucosamina

reguladores de crescimento

\begin{abstract}
R E S U M O
A quitosana, polímero $\beta$-1,4 - ligado de D-glucosamina, tem sido utilizada isoladamente ou associada a fitorreguladores nos protocolos de regeneração de plantas in vitro, como orquídeas e dendezeiro. Entretanto, a funcionalidade deste biopolímero na regeneração in vitro de espécies de algodoeiro ainda é desconhecida. Com intuito de testar a eficácia da quitosana na organogênese direta da cultivar de algodão colorido BRS Rubi, realizou-se experimento utilizando explantes oriundos de nós cotiledonares excisados de plantas matrizes in vitro os quais foram subcultivados em meio MS suplementado com 15,0 $\mathrm{mg} \mathrm{L}^{-1}$ de quitosana isolada ou associada a 3,0 $\mathrm{mg} \mathrm{L}^{-1}$ de 6-benzilaminopurina e distintas concentrações $\left(0,0,0,1,0,5\right.$ e 1,0 $\left.\mathrm{mg} \mathrm{L}^{-1}\right)$ de ácido indolbutírico, ácido naftalenoacético e cinetina. Os cultivos foram mantidos em câmara de crescimento a $25 \pm 2{ }^{\circ} \mathrm{C}$ com fotoperíodo de $16 \mathrm{~h}$ de luz e intensidade luminosa de $40 \mu \mathrm{mol} \mathrm{m}^{-2} \mathrm{~s}^{-1}$ durante 50 dias. As variáveis analisadas foram número de brotos/explante e tamanho do maior broto. Os melhores resultados foram alcançados nos tratamentos suplementados apenas com 6-benzilaminopurina e quitosana, porém a quitosana isolada não induziu o superbrotamento na cultivar estudada.
\end{abstract}

Key words: cv. BRS ruby in vitro culture multiple shoots D-glucosamine growth regulators

\section{Chitosan and phytoregulators on the induction of direct organogenesis in colored cotton cultivar}

\begin{abstract}
A B S T R A C T
Chitosan, polymer $\beta$-1,4 - linked D-glucosamine, has been used alone or combined with growth regulators on plant regeneration protocols in vitro such as orchids and oil palm. However, the functionality of this biopolymer in vitro regeneration of cotton species is still unknown. In order to test the efficacy of the chitosan in direct organogenesis in colored cotton cultivar BRS Rubi, experiment was conducted using explants derived from cotyledonary nodes excised from stock plants in vitro which were subcultured on MS medium supplemented with $15.0 \mathrm{mg} \mathrm{L}^{-1}$ of the chitosan isolated or associated with $3.0 \mathrm{mg} \mathrm{L}^{-1}$ 6-benzylaminopurine and different concentrations $(0,0.1,0.5$ and $1.0 \mathrm{mg} \mathrm{L}^{-1}$ ) butyric acid, naphthalene acetic acid and kinetin. The cultures were kept in a growth chamber at 25 $\pm 2{ }^{\circ} \mathrm{C}$ with a photoperiod of $16 \mathrm{~h}$ light and light intensity of $40 \mu \mathrm{mol} \mathrm{m}^{-2} \mathrm{~s}^{-1}$ for 50 days. The analysed variables were number of shoots/explant and size of the largest shoot. The best results were obtained in the treatments supplemented only with 6-benzylaminopurine and chitosan. However, isolated chitosan did not induce multiple shoots in the studied cultivar.
\end{abstract}

\section{INTRODUÇÃO}

A biotecnologia tem contribuído de forma contundente para produzir cultivares de algodoeiro com características superiores, como resistência a pragas e doenças, precocidade, alta produtividade e fibras naturalmente coloridas. Dentre as cultivares de fibra colorida, Carvalho \& Silva (2009) mencionam a cv. BRS Rubi como sendo a primeira cultivar no país com pluma de cor marrom-avermelhado dispensando os processos químicos de branqueamento e tingimento industrial, agregando maior valor ao produto.

Neste sentido, o cultivo de tecidos in vitro constitui uma importante ferramenta biotecnológica de apoio ao melhoramento genético do algodoeiro, principalmente na perspectiva de obtenção de transgênicos de cultivares nacionais. Com isso, o desenvolvimento de protocolos de regeneração eficazes é decisivo para se obter sucesso na transformação genética e na regeneração da planta através da célula geneticamente modificada. Uma das maiores limitações para o algodoeiro é a forte dependência genotípica (Han et al., 2009) que torna a cultura recalcitrante a diferentes protocolos.

Os reguladores de crescimento são decisivos para o processo de regeneração da planta. As auxinas, como o ANA (ácido naftalenoacético) e o AIB (ácido indolbutírico) 
atuam no crescimento, alongamento e na divisão celular (Nóbrega et al., 1999) enquanto as citocininas, como o BAP (6-benzilaminopurina) e a KIN (cinetina) induzem a multibrotação em gemas axilares ou apicais (Cid et al., 1994). Mushke et al. (2012) mencionam a importância do balanço auxina/citocinina ao verificar a média de 6 a 8 brotos por explante em meio de cultivo suplementado com $0,1 \mathrm{mg} \mathrm{L}^{-1} \mathrm{de}$ ANA e $1,5 \mathrm{mg} \mathrm{L}^{-1}$ de BAP.

$\mathrm{O}$ uso da quitosana na agricultura vem sendo amplamente difundido devido aos seus efeitos benéficos sobre as culturas e o meio ambiente, atuando no crescimento e no desenvolvimento das plantas, no estímulo à imunidade e como fertilizante (Nge et al., 2006). Trata-se de um polissacarídeo composto de $ß-1,4$ $\mathrm{D}$-glucosamina ligada a resíduos de $\mathrm{N}$-acetilglucosamina, naturalmente encontrada na parede do micélio de alguns fungos podendo ser obtido por diacetilação da quitina, principal componente do exoesqueleto dos artrópodes e crustáceos (Fai et al., 2008). Sua funcionalidade em cultivo in vitro de plantas ainda é pouco conhecida e não há estudos que comprovem sua eficácia na regeneração de genótipos de algodoeiro. Entretanto, Nge et al. (2006) e Kanchanapoom et al. (2010) citam, respectivamente, a capacidade da quitosana de estimular a diferenciação de plântulas de orquídeas além de se apresentar potencialmente útil na micropropagação do dendenzeiro.

Neste contexto, o presente estudo objetivou induzir o superbrotamento por organogênese direta em explantes da cv. BRS Rubi e analisar o efeito da quitosana associada a auxinas e citocininas neste processo com o intuito de definir o melhor tratamento para regeneração da cultivar estudada.

\section{Material e Métodos}

O trabalho foi conduzido no Laboratório de Cultura de Tecidos da Embrapa Algodão, Campina Grande, PB.

Para obtenção das plantas matrizes, as sementes da cv. BRS Rubi provenientes do Banco de Germoplasma (BAG) da Embrapa Algodão foram lavadas em água corrente e posteriormente desinfestadas em solução de hipoclorito de sódio comercial a $1 \%(\mathrm{v} / \mathrm{v})$ de cloro ativo, adicionado de duas gotas de Tween-20 para cada $100 \mathrm{~mL}$ da solução. Em câmara de fluxo laminar passaram por três enxagues em água destilada estéril e foram inoculadas em tubos de ensaio contendo $10 \mathrm{~mL}$ de meio MS basal (Murashige \& Skoog, 1962). As sementes foram incubadas na ausência de luminosidade, de 3 a 7 dias e depois mantidas em câmara de crescimento a $25 \pm 2{ }^{\circ} \mathrm{C}$ com fotoperíodo de $16 \mathrm{~h}$ de luz e intensidade luminosa de $40 \mu \mathrm{mol}$ $\mathrm{m}^{-2} \mathrm{~s}^{-1}$ durante quinze dias.

Explantes oriundos de nós cotiledonares foram excisados das plantas matrizes e induzidos ao superbrotamento em meio de cultura com sais e vitaminas de Murashige \& Skoog (1962) suplementado com quitosana, BAP e diferentes concentrações de KIN, AIB e ANA, totalizando 13 tratamentos.

Foram realizadas 10 repetições por tratamento tendo, como unidade experimental, frascos contendo três explantes em delineamento inteiramente casualizado com arranjo fatorial $3 \times 4+1$, ou seja, três tipos de fitorreguladores (ANA, KIN,
AIB) com quatro concentrações distintas $(0,0,0,1,0,5,1,0$ $\left.\mathrm{mg} \mathrm{L}^{-1}\right)$ associados ao $\operatorname{BAP}\left(3,0 \mathrm{mg} \mathrm{L}^{-1}\right)$ e a quitosana $(15,0 \mathrm{mg}$ $\left.\mathrm{L}^{-1}\right)$, mais um controle (MS + quitosana). Os meios de cultura foram suplementados com $3 \%(\mathrm{~m} / \mathrm{v})$ de sacarose, $0,57 \%(\mathrm{~m} / \mathrm{v})$ de ágar e o pH ajustado em 5,7 antes da autoclavagem a 120 ${ }^{\circ} \mathrm{C}$ durante $20 \mathrm{~min}$. Os cultivos foram mantidos em câmara de crescimento a $25 \pm 2{ }^{\circ} \mathrm{C}$ com fotoperíodo de $16 \mathrm{~h}$ de luz e intensidade luminosa de $40 \mu \mathrm{mol} \mathrm{m} \mathrm{m}^{-1}$

Realizaram-se duas avaliações a cada 25 dias após subcultivo para o mesmo meio. As variáveis analisadas foram o número de brotos/explante (NB) e o tamanho do maior broto (TMB). Com auxílio do programa SAS 9.2 (SAS, 2009), os dados foram transformados pela função $\sqrt{(\mathrm{x}+1)}$ e submetidos à análise de variância complementada com comparação de médias pelo teste de Tukey a 0,05 de probabilidade para fator qualitativo e análise de regressão pelo método polinômios ortogonal para fator quantitativo.

Os explantes com os brotos formados foram inoculados em meio MS isento de fitorreguladores durante 30 dias para promover o alongamento. Posteriormente, os brotos foram induzidos ao enraizamento em meio MS suplementado com $0,25 \mathrm{mg} \mathrm{L}^{-1}$ AIA. As plântulas enraizadas foram cultivadas em substrato ( 2 turfa: 1 vermiculita) estéril e permaneceram em câmara de crescimento para se adaptar às condições autotróficas. Em seguida, foram transferidas para casa de vegetação para completarem seu ciclo.

\section{Resultados e Discussão}

Pode-se observar, após 25 dias do primeiro subcultivo, o superbrotamento em explantes submetidos a diferentes tratamentos (Figura 1 A, B, C, D, E). Entretanto, nos meios

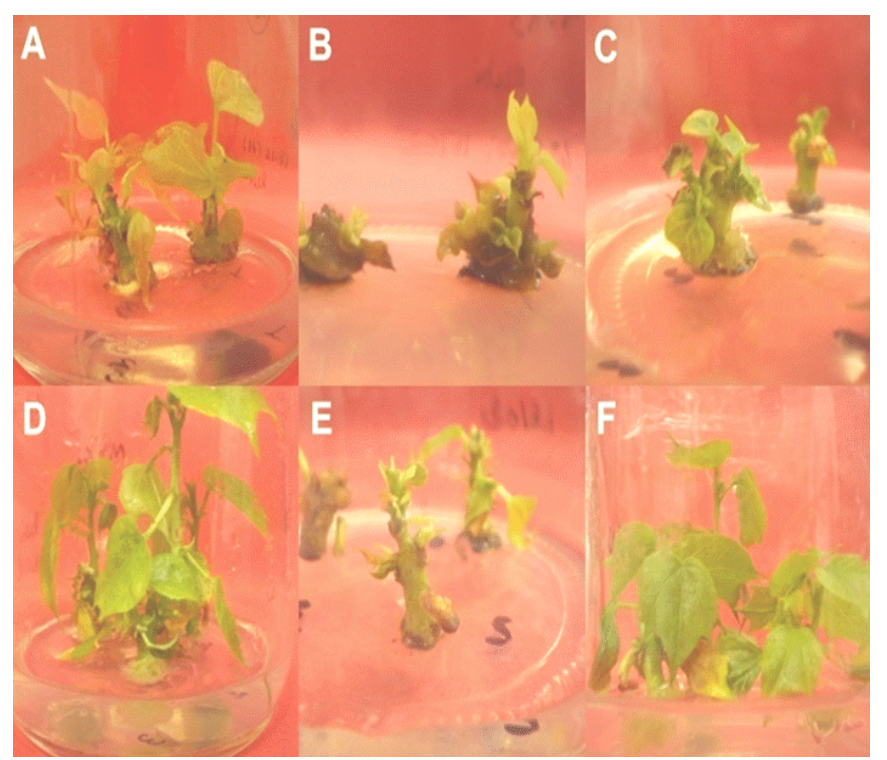

Figura 1. Organogênese in vitro da cv. BRS Rubi: Superbrotamento em explantes subcultivados em meio de cultura (A) MS com BAP + QUI + 0,1 mg $\mathrm{L}^{-1} \mathrm{AIB}$; (B) MS com BAP + QUI + 0,5 mg L $\mathrm{L}^{-1} \mathrm{KIN}$; (C) $\mathrm{MS}$ com BAP + QUI + 0,1 $\mathrm{mg} \mathrm{L}^{-1} \mathrm{ANA}$; (D) (E) MS com BAP + QUI; (F) Controle (MS + $15 \mathrm{mg} \mathrm{L}^{-1}$ Qui) 
suplementados apenas com BAP e quitosana (Figura 1D, E) os explantes produziram maior quantidade de brotos quando comparados aos demais tratamentos. Em contrapartida, os explantes alongaram e se mostraram mais vigorosos quando se utilizou apenas a quitosana, mas não produziram novos brotos (Figura 1F).

A quitosana funcionou, neste caso, como fonte de nitrogênio orgânico mas não influenciou na formação de novos brotos; em contrapartida, estudos realizados com outras culturas sugerem o efeito positivo deste biopolímero na morfogênese in vitro. Kanchanapoom et al. (2012) obtiveram, ao estudar o efeito da quitosana na regeneração de lírio (Lilium longiflorum Thunb) a média de 5 brotos por explante em meio contendo $25,0 \mathrm{mg} \mathrm{L}^{-1}$ de quitosana contra 4,7 brotos em meio com 5,0 $\mathrm{mg} \mathrm{L}^{-1}$ de BAP.

$\mathrm{Na}$ análise dos dados para número de brotos/explante (Tabela 1) os reguladores de crescimento analisados, tal como a relação entre o fatorial e a testemunha, não foram significativos ( $\mathrm{P}>0,05)$; já para os fatores quantitativos, verifica-se diferença significativa $(P<0,01)$ que está relacionada aos efeitos produzidos em relação às diferentes concentrações. Desta forma, a adição dos demais reguladores de crescimento associados ao BAP ou às concentrações em que foram utilizados, não promoveu aumento significativo da quantidade de brotos em relação ao controle que não apresentou superbrotamento.

Observa-se, na Tabela 2, que os melhores resultados para as variáveis número de brotos/explante (NB) e tamanho do maior broto (TMB) foram alcançados nos meios suplementados apenas com a citocinina BAP em que a maior média de brotação foi de 2,11. Os dados obtidos são concordantes com as afirmações de Rodrigues et al. (2012) ao concluírem que o uso de BAP para indução de brotações foi eficiente nas doses entre 3,0 e 5,0 $\mathrm{mg} \mathrm{L}^{-1}$ em explantes de palmeira Astrocaryum aculeatum Meyer. Cordeiro et al. (2004) conseguiram a maior taxa de brotação (2,14 brotos/ explante) com 3,0 $\mathrm{mg} \mathrm{L}^{-1}$ de BAP em explantes de Paricá (Schizolobium amazonicum Huber ex Ducke); Soares et al. (2011) observaram, ao testar três citocininas (BAP, TDZ (Thidiazuron) e KIN) em explantes de mangabeira (Hancornia speciosa Gomes) as melhores respostas organogênicas (1,98 brotos/explante) no meio suplementado com 2,0 $\mathrm{mg} \mathrm{L}^{-1}$ de BAP. Nesta mesma concentração Santos et al. (2005)

Tabela 1. Resumo de análise de variância referente à variável número de brotos/explante (NBt)

\begin{tabular}{|c|c|c|c|c|}
\hline F. V. & G. L. & S. Q. & Q. M. & $F$ \\
\hline $\begin{array}{l}\text { Regulador de } \\
\text { Crescimento }\end{array}$ & 2 & 0,085 & $0,0425^{\mathrm{NS}}$ & 1,416 \\
\hline $\begin{array}{l}\text { Concentrações } \\
\text { Regulador de }\end{array}$ & 3 & 2,09 & $0,699^{* *}$ & 23,3 \\
\hline $\begin{array}{l}\text { crescimento } x \\
\text { Concentrações }\end{array}$ & 6 & 0,68 & $0,113^{\star *}$ & 3,76 \\
\hline $\begin{array}{l}\text { Fatorial } x \\
\text { Controle }\end{array}$ & 1 & 0,0034 & $0,0034^{\mathrm{NS}}$ & 0,113 \\
\hline $\begin{array}{l}\text { ERRO } \\
\text { CV \% }\end{array}$ & 117 & 3,566 & $\begin{array}{l}0,030 \\
9,97\end{array}$ & \\
\hline
\end{tabular}

NSNão significativo $(P>0,01) ;{ }^{* *}$ Significativo $(P<0,01)$
Tabela 2. Valores médios referentes às variáveis número de brotos por explante (NBt) e tamanho do maior broto (TMBt) em resposta a diferentes concentrações de reguladores de crescimento associados a 3,0 $\mathrm{mg} \mathrm{L}^{-1} \mathrm{BAP}+15 \mathrm{mg} \mathrm{L}^{-1} \mathrm{QUI}$

\begin{tabular}{cccccc}
\hline \multirow{2}{*}{ Variáveis } & R. C. & \multicolumn{4}{c}{ Concentrações $\left(\mathbf{m g ~ L}^{-1}\right)$} \\
\cline { 3 - 6 } & & $\mathbf{0}$ & $\mathbf{0 , 1}$ & $\mathbf{0 , 5}$ & $\mathbf{1}$ \\
\multirow{3}{*}{ NBt } & AIB & $1,92 \mathrm{a}$ & $1,86 \mathrm{a}$ & $1,70 \mathrm{~b}$ & $1,66 \mathrm{a}$ \\
& KIN & $2,11 \mathrm{~b}$ & $1,71 \mathrm{a}$ & $1,51 \mathrm{a}$ & $1,65 \mathrm{a}$ \\
& ANA & $1,83 \mathrm{a}$ & $1,77 \mathrm{a}$ & $1,69 \mathrm{ab}$ & $1,58 \mathrm{a}$ \\
\hline \multirow{2}{*}{ TMBt } & AIB & $0,74 \mathrm{~b}$ & $0,67 \mathrm{~b}$ & $0,33 \mathrm{a}$ & $0,29 \mathrm{a}$ \\
& KIN & $1,71 \mathrm{C}$ & $0,37 \mathrm{a}$ & $0,27 \mathrm{a}$ & $0,32 \mathrm{a}$ \\
& ANA & $0,40 \mathrm{a}$ & $0,34 \mathrm{a}$ & $0,26 \mathrm{a}$ & $0,20 \mathrm{a}$ \\
\hline
\end{tabular}

Dados transformados em $\sqrt{ }(x+1)$; Médias seguidas pela mesma letra em cada coluna não diferem entre si pelo teste de Tukey

verificaram, trabalhando com explantes caulinares de Anana erectifolius L. B. Smith, a formação de maior número de brotos (5,83/explante).

Verifica-se, na Figura 2, tendência linear para as auxinas AIB e ANA, ou seja, com o aumento da concentração a média do número de brotos decresce. Resultados similares foram descritos por Brum et al. (2002) estudando o efeito de diferentes concentrações de BAP $\left(0,0 ; 0,5 ; 1 ; 2 ; 4 \mathrm{mg} \mathrm{L}^{-1}\right)$ e ANA $\left(0,0 ; 0,05 ; 0,1 ; 0,2 \mathrm{mg} \mathrm{L}^{-1}\right)$ na propagação in vitro de Figueira (Ficus carica L.) em que o maior número de brotos foi alcançado nas concentrações de 2,0 e 4,0 $\mathrm{mg} \mathrm{L}^{-1}$ de BAP isolado, a adição de ANA não melhorou significativamente a resposta desta variável, exceto $0,1 \mathrm{mg} \mathrm{L}^{-1}$ na ausência de BAP ou 0,1 e $0,2 \mathrm{mg} \mathrm{L}^{-1}$ associados a 1,8 e $2,1 \mathrm{mg} \mathrm{L}^{-1}$ de BAP. Sousa \& Miranda (2006) relataram que a adição de AIB nas concentrações $0,0,0,05$ e $0,5 \mathrm{mg} \mathrm{L}^{-1}$ associado ao BAP ou a KIN não influenciou na proliferação de brotos em explantes de Gerbera jamesonni var. 'ornela embora a concentração de $0,5 \mathrm{mg} \mathrm{L}^{-1}$ dessa auxina tenha propiciado as melhores características para a multiplicação desta variedade.

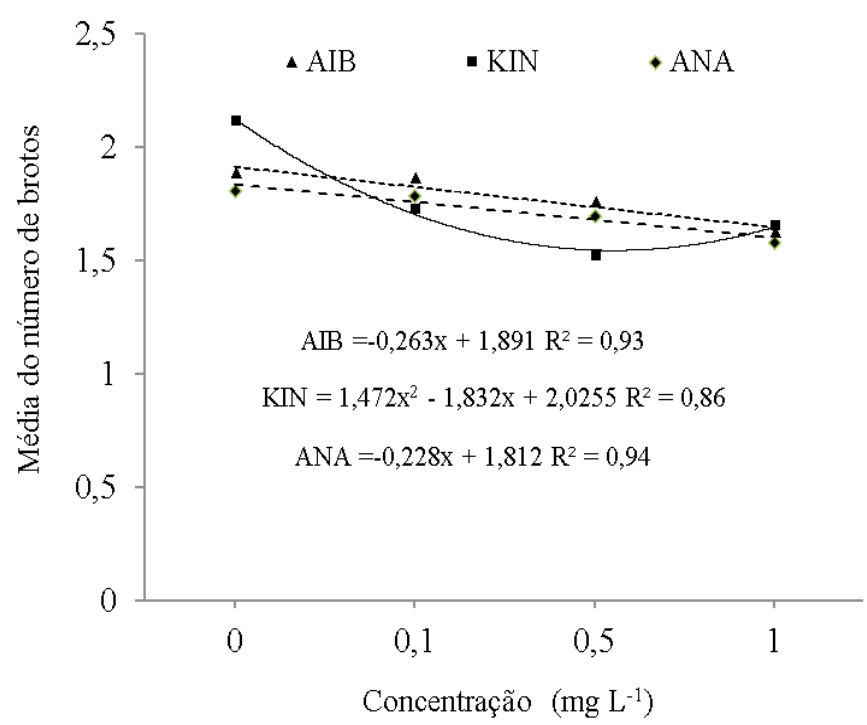

Figura 2. Número de brotos por frasco em relação às concentrações dos reguladores de crescimento (AIB, KIN e ANA) associados a 3,0 $\mathrm{mg} \mathrm{L}^{-1} \mathrm{BAP}+15,0 \mathrm{mg}$ $\mathrm{L}^{-1} \mathrm{QUI}$ 
Para a citocinina KIN pode-se observar, na Figura 2, um modelo quadrático que sugere efeito positivo para a variável número de brotos em concentrações acima de $1,0 \mathrm{mg} \mathrm{L}^{-1}$. O resultado encontrado está de acordo com Nicioli et al. (2008) ao observarem, em explantes de Barbatimão (Stryphnodendron adstringens (Mart.) Coville) que, à medida que se aumentou a concentração de KIN no meio de cultura o número de brotos formados a partir do segmento nodal foi favorecido sendo registrada, portanto, uma resposta melhor (3,0 brotos/ explante) quando foram utilizados $5,0 \mathrm{mg} \mathrm{L}^{-1}$ de KIN.

Estudos realizados com variedades do algodoeiro ressaltam a importância das citocininas na formação de brotos. Carvalho et al. (2006) obtiveram, utilizando a concentração de $3,0 \mathrm{mg} \mathrm{L}^{-1}$ de BAP e 3,0 $\mathrm{mg} \mathrm{L}^{-1}$ de KIN, a média de 5,3 brotos/explantes na cultivar de algodão colorido BRS Verde. Rocha et al. (2008) obtiveram superbrotamento satisfatório em explantes da cultivar BRS-200 adicionando BAP isoladamente ao meio MS nas concentrações 1,0 e 2,0 $\mathrm{mg} \mathrm{L}^{-1} \mathrm{o}$ mesmo foi verificado para a 6M Mocó e BRS-187-8H quando se utilizaram $2 \mathrm{mg} \mathrm{L}^{-1}$ de BAP isolado ou associado a $1,0 \mathrm{mg} \mathrm{L}^{-1}$ de KIN. Em estudo realizado com três cultivares de algodão indiano obteve-se a média de 6-8 brotos/explantes cultivados em meio contendo $1,5 \mathrm{mg} \mathrm{L}^{-1}$ de BAP e $0,1 \mathrm{mg} \mathrm{L}^{-1}$ de ANA (Mushke et al., 2012).

Após a indução os explantes foram subcultivados em meio MS sem regulador de crescimento visando promover o alongamento dos brotos (Figura $3 \mathrm{~A}$ ) em que, ao atingir tamanho superior a $1,0 \mathrm{~cm}$, foram isolados dos explantes e induzidos ao enraizamento em meio MS suplementado

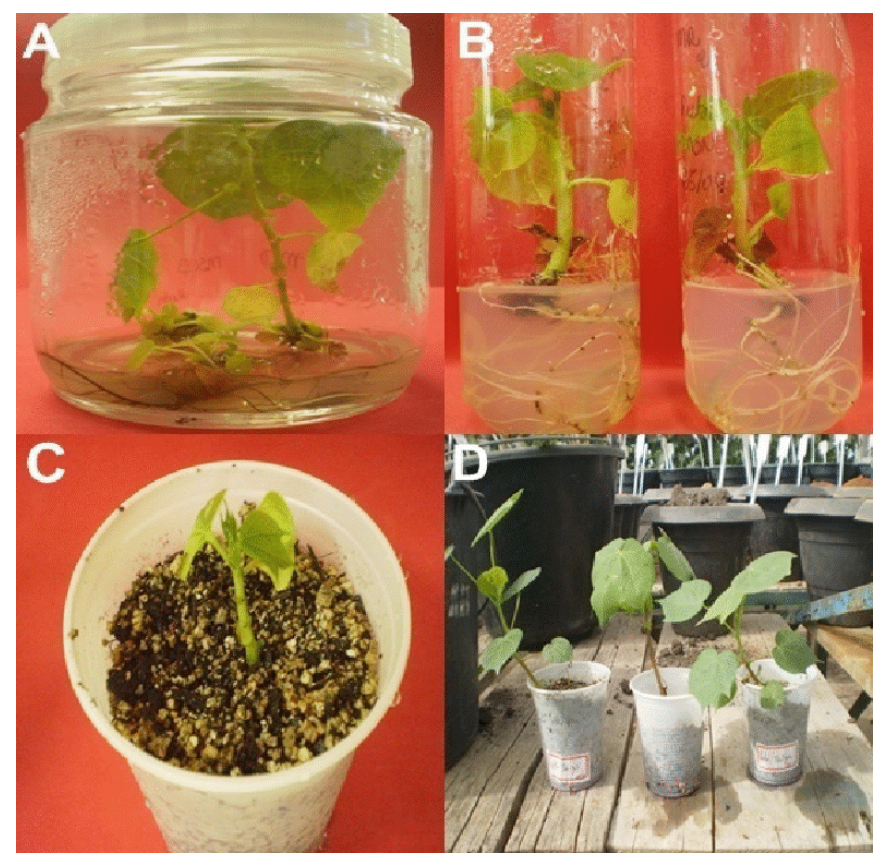

Figura 3. Organogênese in vitro da cV. BRS Rubi. (A) Alongamento em meio MS sem fitorreguladores; (B) Enraizamento dos brotos em meio MS com 0,25 $\mathrm{mg} \mathrm{L}^{-1}$ de AIA; (C) Aclimatização em turfa + vermiculita estéreis; (D) Casa de vegetação (Antes da transferência para vasos) com 0,25 $\mathrm{mg} \mathrm{L}^{-1}$ de AIA (Figura 3B) possibilitando, assim, o desenvolvimento das plantas e posteriormente a aclimatização (Figura 3C) além de subsequente transferência para casa de vegetação (Figura 3D) para completar seu ciclo de desenvolvimento.

Essas etapas são extremamente importantes haja vista se observar o desenvolvimento das plântulas. Além disto, a possibilidade de estudar as plantas regeneradas em casa de vegetação é fundamental para observar sua adaptação ao ambiente ex vitro e o ciclo reprodutivo tais como fenômenos epigenéticos ou variação somaclonal (Cid \& Teixeira, 2010).

\section{Conclusões}

1. A quitosana não atua isoladamente no superbrotamento da cv. BRS Rubi, constituindo apenas uma fonte de nitrogênio orgânico.

2. O 6 - benzylaminopurina é suficiente para promover a brotação em explantes da cv. BRS Rubi; contudo, outras concentrações devem ser testadas para incrementar a taxa de brotação.

3. A cinetina, o ácido indolbutírico e ácido naftalenoacético nas concentrações utilizadas não respondem satisfatoriamente à indução do superbrotamento na cultivar estudada.

\section{Literatura Citada}

Brum, G. R.; Silva, A. B. da; Pasqual, M. Efeito de diferentes concentrações de BAP e ANA na propagação in vitro da figueira (Ficus carica L.). Ciência e Agrotecnologia, v.26, p.1403-1409, 2002.

Carvalho, J. M. F. C.; Pimentel, N. W.; Aires, P. S. R.; Pimentel, L. W. Micropropagação in vitro da cultivar de algodão BRS-Verde via organogênese utilizando as citocininas BAP e KIN. Campina Grande: Embrapa Algodão, 2006. 15p. Boletim de Pesquisa e Desenvolvimento, n. 68.

Carvalho, J. M. F. C.; Silva, M. M. A. Propagação in vitro de algodão via embriogênese somática. Campina Grande: Embrapa Algodão, 2009. 4p. Circular Técnica, 128

Cid, L. P. B.; Illg, R. D.; Piedrabuena, A. E. Regeneration of garlic plants (Allium sativum L., cv "Chonan") via cell culture in liquid medium. In vitro Plant, v.30, p.150-155, 1994.

Cid, L. P. B.; Teixeira, J. B. Explante, meio nutritivo, luz e temperatura. In: Cid, L. P. B. (ed.). Cultivo in vitro de plantas. Brasília: Embrapa Informação Tecnológica, 2010. p.15-49.

Cordeiro, I. M. C. C.; Lameira, O. A.; Ohashi, S. T.; Rosal, L. F. Efeito de BAP sobre a proliferação de brotos in vitro de Schizolobium amazonicum Huber ex Ducke (Paricá). Cerne, v.10, p.118-124, 2004.

Fai, A. E. C.; Stamford, T. C. M.; Stamford, T. L. M. Potencial biotecnológico de quitosana em sistemas de conservação de alimentos. Revista Iberoamericana de Polímeros, v.9, p.435-451, 2008. 
Han, G. Y.; Wang, X. F.; Zhang, G. Y.; Ma, Z. Y. Somatic embryogenesis and plant regeneration of recalcitrant cottons (Gossypium hirsutum). African Journal of Biotechnology, v.8, p.432-437, 2009.

Kanchanapoom, K.; Phongdara, A.; Kanchanapoom, K. The effect of chitosan on the organogenesis of oil palm embryoderived callus. Notulae Botanicae Horti Agrobotanici ClujNapoca, v.38, p.213-217, 2010.

Kanchanapoom, K.; Pimolthai, P.; Kanchanapoom, K. The effect of chitosan on regeneration of lily (Lilium longiflorum Thunb. 'Ester Lily') from bulb scale explants cultured in vitro. Propagation of Ornamental Plants, v.12, p.127-129, 2012.

Murashige, T.; Skoog, F. A revised medium for rapid growth and bioassays with tobacco tissue culture. Physiologia Plantarum, v.15, p.473-497, 1962.

Mushke, R.; Sultana, T.; Pindi, P. K. High frequency regeneration and multiple shoot induction in indian cotton (Gossypium hirsutum L.) cultivar. Research Journal of Agricultural Sciences, v.3, p.1109-1112, 2012.

Nge, K. L.; Nwe, N.; Chandrkrachang, S.; Stevens, W. F. Chitosan as a growth stimulator in orchid tissue culture. Plant Science, v.170, p.1185-1190, 2006.

Nicioli, P. M.; Paiva, R.; Nogueira, R. C.; Santana, J. R. F. de; Silva, L. C.; Silva, D. P. C. da; Porto, J. M. P. Ajuste do processo de micropropagação de barbatimão. Ciência Rural, v.38, p.685-689, 2008.
Nóbrega, L. B.; Vieira, D. J.; Beltrão, N. E. de M.; Azevedo, D. M. P. Hormônios e reguladores do crescimento e do desenvolvimento. In: Beltrão, N. E. de M. (org.). O agronegócio do algodão no Brasil. Campina Grande: Embrapa Algodão, 1999. p.587-602.

Rocha, M. S.; Carvalho, J. M. F. C.; Mata, M. E. R. M. C.; Lopes, K. P. Indução de superbrotamento e regeneração de plantas in vitro, nas cultivares de algodão colorido. Revista Brasileira de Engenharia Agrícola e Ambiental, v.12, p.503-506, 2008.

Rodrigues, P. H. V.; Ferreira, F. F.; Ambrosano, G. M. B.; Gato, A. M. G. Propagação in vitro de tucumã do Amazonas. Ciência Rural, v.43, p.55-59, 2012.

Santos, A. S. de A.; Machado, I. S.; Leão, A. L.; Ramos, A. de. A. Concentrações de BAP e TDZ na propagação in vitro de Carauá (Ananas erectifolius L. B. Smith). Biotecnologia Ciência \& Desenvolvimento, n.35, p.62-65, 2005.

SAS Institute Inc. SAS Online Doc ${ }^{\oplus}$ 9.2. Cary: SAS, Institute Inc. 2009.

Soares, F. P.; Paiva, R.; Alvarenga, A. A. de; Nery, F. C.; Vargas, D. P.; Silva, D. R. G. Taxa de multiplicação e efeito residual de diferentes fontes de citocinina no cultivo in vitro de Hancornia speciosa Gomes. Ciência e Agrotecnologia, v.35, p.152-157, 2011.

Sousa, C. M.; Miranda, R. M. Otimização do balanço entre auxina e citocinina para multiplicação in vitro de gerbera jamesonni var. 'ornela'. Agronomia, v.40, p.66-72, 2006. 